\title{
Tradeoffs between immune function and childhood growth among Amazonian forager-horticulturalists
}

\author{
Samuel S. Urlachera, Peter T. Ellison ${ }^{\mathrm{b}, 1}$, Lawrence S. Sugiyama ${ }^{\mathrm{c}}$, Herman Pontzer ${ }^{\mathrm{a}, \mathrm{d}}$, Geeta Eick ${ }^{\mathrm{c}}$, Melissa A. Liebert ${ }^{\mathrm{e}}$, \\ Tara J. Cepon-Robins ${ }^{f}$, Theresa E. Gildnerc, and J. Josh Snodgrass ${ }^{c}$

\begin{abstract}
${ }^{a}$ Department of Anthropology, Hunter College, City University of New York, New York, NY 10065; ${ }^{b}$ Department of Human Evolutionary Biology, Harvard Duke University, Durham, NC 27708; 'Department of Anthropology, Northern Arizona University, Flagstaff, AZ 86011; and f Department of Anthropology, University of Colorado, Colorado Springs, CO 80918
\end{abstract} \\ University, Cambridge, MA 02138; 'Department of Anthropology, University of Oregon, Eugene, OR 97403; 'Department of Evolutionary Anthropology,
}

Contributed by Peter T. Ellison, March 14, 2018 (sent for review October 9, 2017; reviewed by Michael Muehlenbein and Barbara A. Piperata)

Immune function is an energetically costly physiological activity that potentially diverts calories away from less immediately essential life tasks. Among developing organisms, the allocation of energy toward immune function may lead to tradeoffs with physical growth, particularly in high-pathogen, low-resource environments. The present study tests this hypothesis across diverse timeframes, branches of immunity, and conditions of energy availability among humans. Using a prospective mixed-longitudinal design, we collected anthropometric and blood immune biomarker data from 261 Amazonian forager-horticulturalist Shuar children (age 4-11 y old). This strategy provided baseline measures of participant stature, s.c. body fat, and humoral and cell-mediated immune activity as well as subsample longitudinal measures of linear growth (1 wk, $3 \mathrm{mo}, 20 \mathrm{mo}$ ) and acute inflammation. Multilevel analyses demonstrate consistent negative effects of immune function on growth, with children experiencing up to $49 \%$ growth reduction during periods of mildly elevated immune activity. The direct energetic nature of these relationships is indicated by $(i)$ the manifestation of biomarker-specific negative immune effects only when examining growth over timeframes capturing active competition for energetic resources, (ii) the exaggerated impact of particularly costly inflammation on growth, and (iii) the ability of children with greater levels of body fat (i.e., energy reserves) to completely avoid the growth-inhibiting effects of acute inflammation. These findings provide evidence for immunologically and temporally diverse body fat-dependent tradeoffs between immune function and growth during childhood. We discuss the implications of this work for understanding human developmental energetics and the biological mechanisms regulating variation in human ontogeny, life history, and health.

life history theory | energetics | phenotypic plasticity | inflammation | adaptive immunity

ife history theory posits that organisms allocate energy (i.e., Lcalories) to primary life tasks such as somatic maintenance, growth, reproduction, and physical activity in a manner that maximizes fitness $(1,2)$. Under this framework, energy availability is limited, patterns of energy allocation are dynamic, and functional tradeoffs between competing metabolic tasks are expected to occur. A powerful analytical approach, life history tradeoff analysis has been invoked to explain phenotypic variation across a range of taxa and ecological contexts $(3,4)$.

Immune function is an essential and particularly costly life task (5). Severe immunological responses can more than double basal energy expenditure (6), and even mild, nonfebrile immune activity is accompanied by an $8-14 \%$ increase in resting metabolic rate (7). In recognition of this substantial cost, research investigating the role of immune energetics as a driver of phenotypic plasticity has flourished. This work provides considerable evidence for tradeoffs between immune function and competing life tasks among nonhuman vertebrate and invertebrate species
(8-10). Direct evidence for immune-related tradeoffs among humans, however, remains sparse.

Energetic tradeoffs involving human immune function are likely to occur during childhood, a life stage unique to the genus Homo (11) and characterized by considerable energy constraint $(12,13)$. Physical growth is expected to be particularly sensitive to immune-related tradeoffs at this time (14). However, while the adverse effect of illness on child linear growth has long been recognized (15), the direct role of energetic tradeoffs with immune function in driving this relationship remains unclear. Few studies have prospectively examined the impact of low-level immune activity-characterizing the majority of child immune responses globally (16) - on growth or have investigated the timeframes (e.g., days, months, or years) over which such tradeoffs may occur in response to diverse forms of pathogen defense.

Body fat plays a critical role in meeting energy shortfalls among humans $(13,17)$ and may serve to buffer or mask expected tradeoffs between competing metabolic tasks $(18,19)$. Human adipose levels reach a nadir between the ages of 3-7 y (20), however, and the importance of body fat as a moderator of energetic tradeoffs during childhood is unclear. This limitation is due in large part to a lack of targeted longitudinal research outside of energy-abundant industrialized populations. Tradeoffs

\section{Significance \\ The energetic impact of immune function on human growth re- mains unclear. Using data from Amazonian forager-horticulturalists, we show that diverse, low-level immune activity predicts re- duced childhood growth over periods of competing energy use ranging from $1 \mathrm{wk}$ to $20 \mathrm{mo}$. We also demonstrate that modest body fat stores (i.e., energy reserves) protect children from the particularly detrimental impact of acute inflamma- tion on growth. These findings provide evidence for consider- able energetic tradeoffs between immune function and growth among humans, highlighting the energy constraint of childhood and the characteristic ability of our species to respond sensitively to dynamic environmental conditions. We outline the possible role of immune-related tradeoffs in driving patterns of human growth faltering, developmental metabolic plasticity, and life history evolution.}

Author contributions: S.S.U., P.T.E., L.S.S., and J.J.S. designed research; S.S.U., L.S.S., G.E M.A.L., T.J.C.-R., and T.E.G. performed research; S.S.U. contributed new reagents/analytic tools; S.S.U. and P.T.E. analyzed data; and S.S.U., P.T.E., L.S.S., H.P., and J.J.S. wrote the paper.

Reviewers: M.M., Baylor University; and B.A.P., The Ohio State University.

The authors declare no conflict of interest.

Published under the PNAS license.

${ }^{1}$ To whom correspondence should be addressed. Email: pellison@fas.harvard.edu.

This article contains supporting information online at www.pnas.org/lookup/suppl/doi:10. 1073/pnas.1717522115/-/DCSupplemental.

Published online April 9, 2018. 
between immune function and childhood growth, as well as the ability of body fat to mitigate such tradeoffs, should be most evident among subsistence-based populations for whom energy availability is limited and environmental pathogenicity is severe $(21,22)$. Research in such contexts is needed to illuminate the basic biological mechanisms regulating variation in human ontogeny, life history, and health.

The present study investigates tradeoffs between immune function and childhood growth among the Shuar, an indigenous forager-horticulturalist population from Amazonian Ecuador. The Shuar experience dietary energy constraint (23), high rates of infectious and parasitic disease (24-26), and slow rates of physical growth (27). The relationships between these traits, however, have been only preliminarily explored (19). We collected data from 261 children (4-11 y old). To broadly assess child immune function, we measured four sensitive blood biomarkers, each reflecting a distinct form of pathogen defense and profile of expected energy use (i.e., duration and magnitude of energetic investment in immune function) (Table 1). To examine the timeframes over which immune-related impacts on growth occur, we utilized a prospective mixed-longitudinal design capturing relationships between immune activity at baseline and current stature as well as growth in height over subsequent 3-mo and 20-mo periods and growth in lower leg length over 1-wk intervals using well-validated knemometry (28-30). Mixed models were constructed to test the hypothesis that energetic tradeoffs occur between immune function and growth during childhood. We test three specific predictions: (P1) Tradeoffs are contingent upon synchrony of energy competition, such that negative relationships between immune function and growth are evident only when assessed durations of growth and immune function (indicated by each biomarker) are similar (Table 1); (P2) Tradeoffs are contingent upon the degree of energy competition, such that negative relationships between immune function and growth are intensified when expected immune function costs (indicated by each biomarker) are greater (Table 1); and (P3) Tradeoffs are buffered by somatic energy stores, such that immune function has a less detrimental effect on growth among children with greater body fat.

\section{Results}

Descriptive sample characteristics are presented in Tables 2 and 3. Participants were short and light compared with US references (31) and grew at rates typical of Amazonian forager-horticulturalists
$(18,27,28,32)$. In total, $42 \%$ of children were classified as stunted [i.e., US height-for-age z-score (HAZ) equal to or less than -2]. Immune biomarkers indicate an overall high degree of immune activity, with mean circulating concentrations approximating values previously reported for the Shuar (19) and children from other nonindustrialized populations (33-36).

Immune Function Effects on Growth. As predicted, mixed-effects analyses controlling for age, sex, and additional covariates ( $\mathrm{Ma}$ terials and Methods) demonstrate that greater immune activity at baseline was associated with lower HAZ and reduced subsequent growth across all durations assessed (Table 4). Negative impacts on growth corresponded closely with the known time courses of immune biomarkers, with relationships detected only between measures of immunity and growth reflecting similar durations of expected energy use (P1) (Fig. 1). Moreover, immune biomarkers reflecting more costly forms of immune function were associated with larger impacts on growth (P2). These results were consistent when using alternative $\triangle \mathrm{HAZ}$ outcome measures (Table S1) and when controlling for additional household income, style of life, and dietary indices (Table S2).

A concentration of C-reactive protein $(\mathrm{CRP}) \geq 1 \mathrm{mg} / \mathrm{L}$, a measure of acute immune activity indicating mild, but costly, systemic inflammation over a period of only days (Materials and Methods and ref. 37), negatively predicted 1-wk growth, such that elevated CRP at baseline was associated with a $0.16-\mathrm{mm}(22.9 \%)$ decrease in growth over the following week among all participants ( $\mathrm{SE}=0.08, P=0.048$ ) (Fig. $2 A$ ). As predicted, CRP elevation had no impact on longer measures of 3-mo growth $(P=$ 0.173), 20-mo growth $(P=0.393)$, or HAZ $(P=0.802)$.

Epstein-Barr virus antibody (EBV-Ab) concentration, an inverse measure of cell-mediated immunity over an intermediate period of several weeks (38), was not predictive of growth in any model (all $P>0.1$ ).

Total IgG level, an intermediate-duration measure of adaptive humoral immune function against viruses and bacteria over a period of several months (39), negatively predicted corresponding 3-mo growth $(\beta=-0.55, \mathrm{SE}=0.17, P=0.002)$. A 1 -SD increase in natural $\log$-transformed $\operatorname{IgG}(\ln -\mathrm{IgG})$ at baseline was related to a $0.15-\mathrm{cm}(12.4 \%)$ reduction in growth over the subsequent 3-mo period (Fig. $2 B$ ) but had no effect on 1-wk growth $(P=0.120), 20$-mo growth $(P=0.101)$, or HAZ $(P=0.082)$. The relationship between $\ln -\operatorname{IgG}$ and 3-mo growth remained when two outlier $\ln -\mathrm{IgG}$ values $(0.97$ and $1.08 \mathrm{~g} / \mathrm{L})$ were removed from the analysis $(\beta=-0.55, \mathrm{SE}=0.19, P=0.004)$.

Table 1. Immune function biomarkers and predicted relationships to growth

\begin{tabular}{|c|c|c|c|c|c|}
\hline Biomarker & Description & Time course* & $\begin{array}{c}\text { Predicted } \\
\text { growth affected }\end{array}$ & Energy cost ${ }^{\dagger}$ & $\begin{array}{c}\text { Predicted growth } \\
\text { tradeoff }\end{array}$ \\
\hline CRP & $\begin{array}{l}\text { Acute-phase protein involved in inflammation, providing } \\
\text { a nonspecific first line of defense against pathogens and } \\
\text { injury; a direct measure of innate immune activity. }\end{array}$ & Days & $1 \mathrm{wk}$ & High & Large \\
\hline$E B V-A b$ & $\begin{array}{l}\text { Antibody produced specifically in response to the nearly } \\
\text { ubiquitous Epstein-Barr herpesvirus; an indirect (and inverse) } \\
\text { measure of the cell-mediated immune activity that is } \\
\text { responsible for maintaining viral latency. }\end{array}$ & Weeks & $3 \mathrm{mo}$ & Moderate & Moderate \\
\hline $\lg G$ & $\begin{array}{l}\text { Class of antibody produced predominantly in response to } \\
\text { viruses and bacteria; a direct measure of adaptive humoral } \\
\text { immune activity. }\end{array}$ & Months & $3 \mathrm{mo}$ & Moderate & Moderate \\
\hline $\lg \mathrm{E}$ & $\begin{array}{l}\text { Class of antibody produced predominantly in response to } \\
\text { macroparasites (e.g., helminths); a direct measure of adaptive } \\
\text { humoral immune activity. }\end{array}$ & Years & $\begin{array}{l}20 \text { mo; height- } \\
\text { for-age }\end{array}$ & Low & Small \\
\hline
\end{tabular}

Each biomarker indicates a distinct form of pathogen defense and associated energetic profile (i.e., duration and magnitude of metabolic energy use inferred from a single measure).

*Typical duration of response from stimulation to return to blood baseline concentration (37-40).

${ }^{\dagger}$ Expected relative energetic cost (in kilocalories per day) of indicated immune function $(5,42,43)$. 
Table 2. Anthropometry sample characteristics

\begin{tabular}{lcc} 
Measure & $N$ & Mean (SD) \\
\hline Age, y & 261 & $8.30(1.98)$ \\
HAZ* & 261 & $-1.80(0.84)$ \\
Weight-for-age z-score* & 261 & $-1.05(0.77)$ \\
Sum of four skinfolds, mm & 261 & $23.3(5.2)$ \\
20-mo height growth, cm & 85 & $8.18(1.47)$ \\
3-mo height growth, cm & 177 & $1.21(0.61)$ \\
1-wk lower leg growth, mm & 244 & $0.66(0.55)$ \\
\hline
\end{tabular}

*Z-scores calculated from US CDC references (31).

Total IgE level, a measure of chronic, relatively low-cost, antiparasite adaptive immune function over a period of several years (40), was negatively related to the long-term measures of HAZ $(\beta=-0.11, \mathrm{SE}=0.05, P=0.032)$ and 20 -mo growth $(\beta=-0.37, \mathrm{SE}=0.16, P=0.022)$, such that a $1-\mathrm{SD}$ increase in ln-IgE concentration at baseline was associated with a 0.11 -unit decrease in HAZ (Fig. 2D) and a $0.37-\mathrm{cm}(4.5 \%)$ decrease in growth over the following 20 mo (Fig. $2 C$ ). Levels of IgE were not related to more acute measures of 1 -wk growth $(P=0.128)$ or 3-mo growth $(P=0.608)$.

Body Fat Moderation of Immune Function Effects. To examine the role of body fat in buffering tradeoff effects, children were categorized into high or low body fat groups (Materials and Methods). As predicted (P3), body fat group significantly moderated the relationship between $\mathrm{CRP}$ and 1 -wk growth $(\beta=0.40, \mathrm{SE}=$ $0.16, P=0.013)$. Elevated CRP at baseline was associated with a $0.34-\mathrm{mm}(49.3 \%)$ reduction in growth over the ensuing week among children with relatively low body fat $(\mathrm{SE}=0.11, P=$ 0.002 ) but, in contrast, no reduction in growth was seen among those with elevated CRP and relatively high body fat $(\beta=-0.06$, $\mathrm{SE}=0.12, P=0.590)$ (Fig. 3). These results remained significant in analyses using alternative CRP cutoff values (Table S3), CRP data restricted to $<5 \mathrm{mg} / \mathrm{L}$ (Table $\mathrm{S} 4$ ), and continuous residual skinfolds measures of body fat (Fig. S1 and Table S5). Significant body fat moderating effects were restricted to the particularly strong relationship between CRP and 1-wk growth (all other models $P>0.05)$.

\section{Discussion}

This study provides evidence for considerable tradeoffs between immune function and growth among humans. A strength of this research is our investigation of four sensitive immune biomarkers, each quantifying functionally distinct, low levels of immune activity that, while metabolically costly, likely do not result in anorexia, physical inactivity, or other energetically relevant symptoms of infection $(35,41)$ that could obscure tradeoff relationships. Using a mixed-longitudinal design, we have shown that Shuar children experiencing relatively greater immune activity were shorter than their peers and grew considerably less over periods ranging from $1 \mathrm{wk}$ to $20 \mathrm{mo}$. In support of the hypothesis that these relationships are driven by direct competition for energetic resources, negative associations between specific measures of immunity and growth were stronger when involving more costly forms of immune function and were evident only when examined over timeframes corresponding to synchronous energy use. Moreover, children with greater body fat were able to completely avoid the detrimental effects of acute inflammation on 1-wk growth, suggesting that childhood adipose energy reserves play a critical role in buffering immune-related tradeoffs. These findings have implications for understanding human developmental plasticity, life history, and health.
Tradeoffs Between Immune Function and Childhood Growth Are Immunologically and Temporally Diverse. Different forms of immune function entail different physiological profiles, each implying unique temporal and absolute patterns of energy use (5, 39). The biomarkers investigated in this study reflect the immunological diversity that spans these patterns. We have demonstrated that the effects of specific forms of immune activity on growth are consistent with expected energy use and transpire across a wide range of timeframes. Notably, we have found that acute and energetically costly $(5,42)$ inflammation (i.e., CRP elevation) exhibits a particularly detrimental effect on corresponding short-term growth. Apparent tradeoffs become progressively less dramatic as immune function becomes more chronic, culminating in the comparatively modest impact of longterm, low-cost $(5,43)$ antiparasite humoral immune activity (i.e., IgE levels) on 20-mo growth and HAZ. These findings indicate that energetic tradeoffs between immune function and growth result from the activity of multiple forms of immunity. They also highlight the need for research investigating immune-related tradeoffs to obtain measures of immune function and competing life tasks that reflect synchronous expected energy use. This latter observation may clarify the mixed results of previous studies, which have reported relationships between immune biomarkers and child growth in some cases (e.g., refs. 18 and 19) but not others (e.g., refs. 33 and 36). The lack of a relationship between cell-mediated immune function (i.e., EBV-Ab levels) and growth in the present study may similarly reflect poor correspondence of time courses. Alternatively, this finding may result from the observation that EBV-Ab levels, similar to those of CRP (37), can be impacted by stimuli other than antigen exposure (38). Infection status and history, via effects on acquired immunity, may also lead to individual and population-level differences in experienced tradeoffs with growth.

Inflammation-Related Tradeoffs with Childhood Growth Are Buffered by Body Fat and May Have Lifetime Metabolic Effects. The large effect of elevated CRP on child short-term growth is consistent with research involving in vitro models and chronic inflammatory diseases indicating that CRP and upstream proinflammatory cytokines inhibit bone growth via multiple direct and indirect pathways (44). Results further suggest that body fat plays an important role in moderating this relationship: Shuar children with above-median levels of adiposity who experienced elevated CRP were able to completely avoid the $49 \%$ decrease in 1-wk growth faced by thinner children. This finding highlights the primary function of body fat in meeting energy shortfalls among humans $(13,17-19)$. Identifying the regulatory pathways through which body fat exerts a buffering effect on inflammation-related tradeoffs is an important area of future investigation. The cytokine-like hormone leptin, produced by adipocytes in association with total fat mass (45) and demonstrating positive direct and indirect effects on bone growth (46), represents a promising endocrine target for this research.

Early-life energetic experiences have lasting impacts on phenotype (47-49). In recognition of a body fat-dependent relationship with growth, we follow others (50) in proposing that

Table 3. Immune biomarker sample characteristics

\begin{tabular}{lcc} 
Biomarker & $N$ & Geometric mean $( \pm 2 \mathrm{SD})^{*}$ \\
\hline $\mathrm{CRP}, \mathrm{mg} / \mathrm{L}$ & 460 & $0.22(0.01-5.58)$ \\
$\mathrm{CRP} \geq 1 \mathrm{mg} / \mathrm{L}$ & 460 & $25.4 \%$ \\
$\mathrm{EBV}-\mathrm{Ab}, \mathrm{U} / \mathrm{mL}$ & 261 & $87(13-566)$ \\
$\mathrm{IgG}, \mathrm{g} / \mathrm{L}$ & 261 & $7.1(4.2-12.2)$ \\
$\mathrm{IgE}, \mathrm{ng} / \mathrm{mL}$ & 261 & $4,949(670-36,574)$ \\
\hline
\end{tabular}

*Geometric mean ( \pm 2 SD from In-transformed mean). 
Table 4. Mixed-effects models investigating relationships between immune biomarkers and growth

\begin{tabular}{|c|c|c|c|c|}
\hline Parameter & $\begin{array}{l}\text { 1-wk growth, mm } \\
(n=132, \text { obs }=244)\end{array}$ & $\begin{array}{l}\text { 3-mo growth, } \\
\text { cm }(n=177)\end{array}$ & $\begin{array}{c}\text { 20-mo growth, } \\
\mathrm{cm}(n=85)\end{array}$ & $\begin{array}{l}\text { Height-for-age }^{\dagger} \\
\quad(n=261)\end{array}$ \\
\hline \multicolumn{5}{|l|}{ Fixed effects, $\beta$ (SE) } \\
\hline \multicolumn{5}{|l|}{ Immune activity } \\
\hline $\mathrm{CRP} \geq 1 \mathrm{mg} / \mathrm{L}$ & $-0.34(0.11)^{\star *}$ & $0.15(0.11)$ & $0.31(0.36)$ & $-0.03(0.12)$ \\
\hline In EBV-Ab, U/mL & $0.06(0.04)$ & $0.01(0.05)$ & $0.05(0.17)$ & $-0.04(0.05)$ \\
\hline In IgG, g/L & $-0.20(0.13)$ & $-0.55(0.17)^{\star *}$ & $0.98(0.59)$ & $-0.33(0.19)$ \\
\hline $\ln \mathrm{IgE}, \mathrm{ng} / \mathrm{mL}$ & $0.05(0.03)$ & $-0.02(0.05)$ & $-0.37(0.16)^{\star}$ & $-0.11(0.05)^{\star}$ \\
\hline \multicolumn{5}{|l|}{ Body fat and interactions } \\
\hline Skinfolds $>$ median & $0.02(0.09)$ & $0.03(0.09)$ & $0.31(0.32)$ & $0.24(0.10)^{\star}$ \\
\hline CRP $\times$ skinfolds & $0.40(0.16)^{*}$ & - & - & - \\
\hline \multicolumn{5}{|l|}{ Covariates } \\
\hline Age, y & $-0.03(0.02)$ & $0.02(0.02)$ & $-0.14(0.08)$ & $-0.00(0.02)$ \\
\hline Male sex & $0.01(0.08)$ & $-0.12(0.09)$ & $-0.64(0.30)^{\star}$ & $-0.10(0.10)$ \\
\hline UV geographical region & - & - & - & $-0.37(0.13)$ \\
\hline \multicolumn{5}{|l|}{ Random effects, $\sigma^{2}$ (SD) } \\
\hline Community & $0.00(0.06)$ & $0.06(0.25)$ & $0.12(0.35)$ & $0.01(0.07)$ \\
\hline Participant & $0.01(0.10)$ & - & - & - \\
\hline
\end{tabular}

$n$, number of participants; obs, number of observations. Boldface values indicate significant effects. ${ }^{*} P<0.05 ; * * P<0.01$.

${ }^{\dagger} Z$-scores calculated from Shuar population-specific growth references (27).

recurrent inflammation during childhood may have lifetime developmental effects on metabolism, energy use, and health. It is now widely documented that poor childhood growth is associated with an increased propensity for fat deposition (51) and greater risk of later life obesity (52), a relationship that appears to be mediated largely by reduced capacity for dietary fat oxidation (53-55). This dual burden of poor childhood growth and adult obesity is thought by some to reflect an adaptive adjustment early in life to a "thrifty" metabolic phenotype that promotes fat accumulation to hedge against future energy deficits $(17,53,55)$. In light of our findings, we propose that inflammation and energetic tradeoffs between immune function and growth may play a key role in driving this developmental plasticity. Specifically, we suggest that the frequency of acute inflammation during early life serves as an honest signal of environmental pathogenicity and, thus, future immunological energy demands. In response to recurrent inflammation, it may therefore be advantageous for metabolism to respond flexibly within a genetically defined norm of reaction to preferentially store body fat to meet subsequent immune-related energy costs and avoid further deficits to growth. Such a response would be adaptive during childhood but could lead to obesity and poor metabolic health later in life should energetic conditions change (e.g., in association with economic development). This inflammationtradeoff hypothesis for explaining the dual burden paradox is supported by several lines of evidence, including the ubiquity of recurrent inflammation among children in the developing world (16), the increased deposition of immunologically important central body fat (56) during both chronic inflammation and stunting $(51,57)$, and the negative effect of proinflammatory cytokines on circulating levels of insulin-like growth factor-1 (58), itself critical in promoting fat oxidation (59). It is possible that epigenetic (60) and gut microbial (61) changes triggered by earlylife inflammation moderate this pathway. Future study must account for these factors and combine repeated measures of inflammation, growth, body composition, and diet with direct energetic analyses.

Implications for the Etiology of Growth Faltering. This study provides insight into the poorly understood etiology of growth faltering currently affecting over 171 million children globally (62), indicating that energetic tradeoffs with immune function considerably

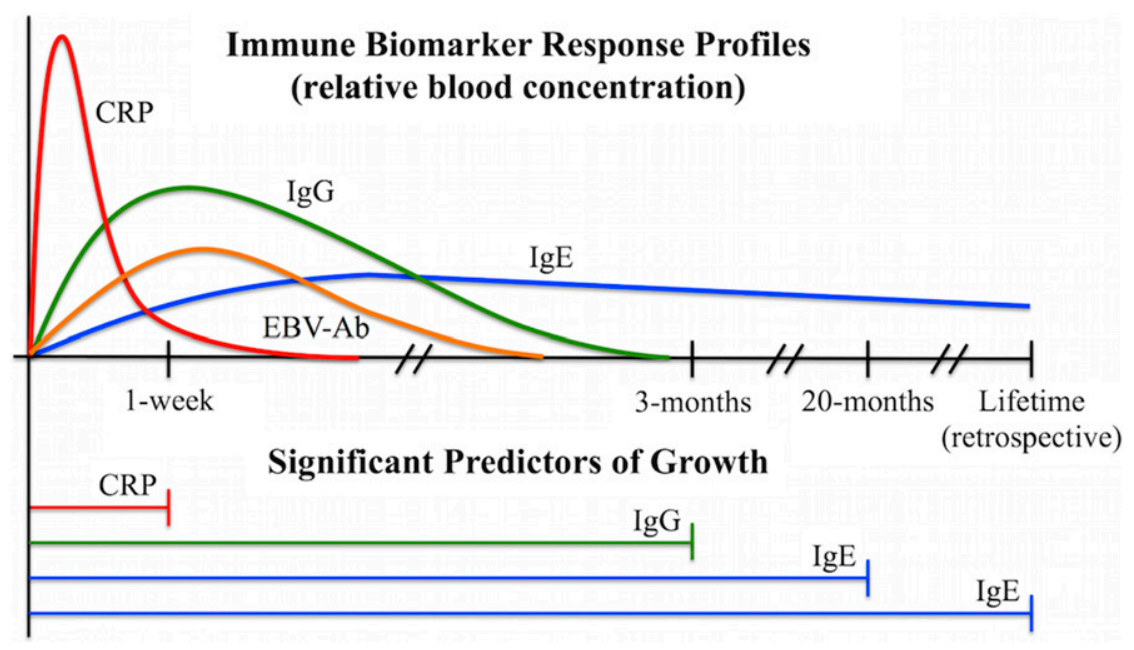

Fig. 1. Diagram illustrating the correspondence between immune biomarker approximate physiological time courses (i.e., duration of indicated energy use following stimulation) (Upper) and significant predictors of growth in mixed-effects models (Lower). 

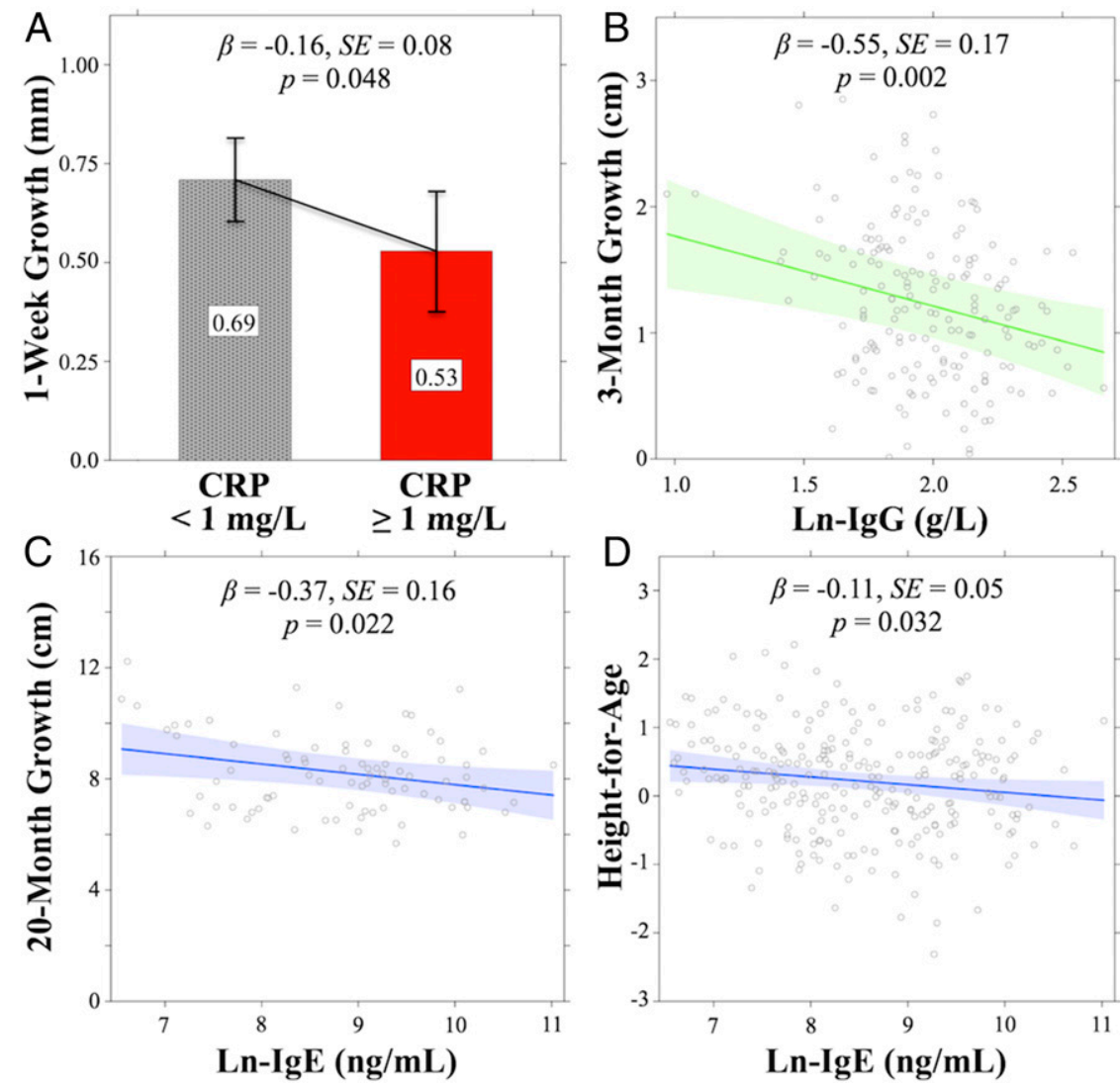

Fig. 2. Mixed-effects model results (estimates, $95 \% \mathrm{Cls}$ ) illustrating significant main effects of immune biomarkers on growth. (A) CRP vs. 1-wk growth. (B) IgG vs. 3-mo growth. (C) IgE vs. 20-mo growth. (D) IgE vs. height-for-age. Concentration of EBV-Ab was not significantly related to growth in any model.

impair growth. Among the Shuar, immune-related tradeoffs appear to explain much of the $\sim 1-\mathrm{cm} / \mathrm{y}$ growth rate deficit that children face relative to international standards (27) as well as the modest secular increase in stature accompanying economic development (63). While recurrent inflammation has long been suggested as a pathway to growth faltering $(16,64)$, testing of this hypothesis has been limited by an inability to monitor short-term growth in field settings. Using knemometry, we provide direct evidence for this hypothesis and the irregular nature of individual short-term growth $(30,65)$. The role of modest levels of body fat in buffering the effect of inflammation on growth underscores the close relationship between malnutrition and infection in

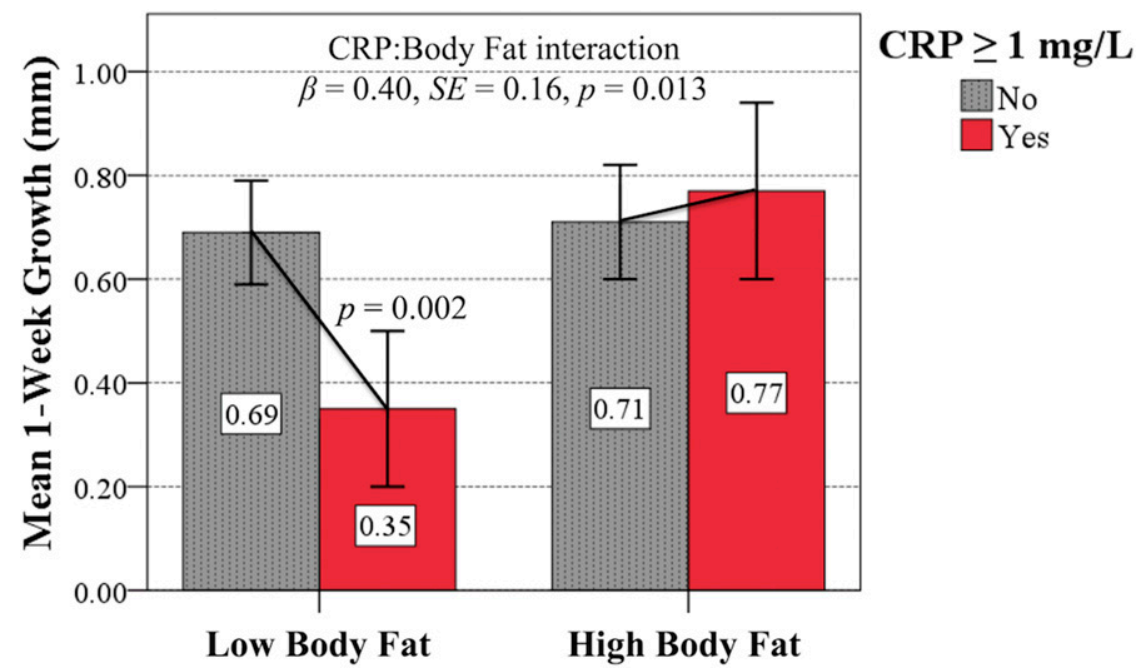

Fig. 3. Mixed-effects model results (estimated means, $95 \% \mathrm{Cls}$ ) illustrating the significant buffering effect of high (i.e., above the median) body fat on the relationship between elevated CRP concentration and subsequent 1-wk growth. Effects were consistent in models using alternative CRP cutoff values and continuous body fat measures. 
childhood stunting (64). While we found no impact of market food consumption on relationships between immune function and growth, detailed macronutrient and micronutrient analyses are needed to isolate dietary effects. Interactions between immunerelated tradeoffs and other factors influencing growth, such as environmental enteric dysfunction (66) and physical activity levels (67), also warrant further study. Interestingly, we found no evidence for catch-up growth in the present sample (i.e., child HAZ did not predict subsequent growth in any model). Long-term longitudinal analyses will clarify these findings and illuminate the lasting impact of immune-related tradeoffs on body size.

Implications for Human Life History, Adaptation, and Evolution. Our findings suggest that, in addition to the energetic demands of developing a large and complex brain (12), immune activity considerably constrains the energy available for childhood growth (14). Slow growth and resultant small body size during development may reduce the risk of starvation by lowering somatic maintenance costs (68). Recognizing the fitness benefits of large adult body size $(21,69)$ and the close relationship between female skeletal and reproductive maturation (70) in our species, we suggest that immune-related energetic constraints on growth may also contribute to global variation in human life history patterns (reviewed in ref. 71) by fostering extended periods of development and delayed maturation under energetically challenging conditions $(27,72)$. While speculative, immune-related energy constraint may have played a similar role in the evolution of extended subadulthood and a unique childhood life stage in the genus Homo (11), particularly given lifestyle changes (e.g., home-base foraging, enhanced sociality, increased physical activity) expected to elevate pathogen exposure in parallel with the evolution of increased brain size, body fat, and metabolic rate (17, 73-75). Comparative data are needed to determine if the acute sensitivity of growth to immune function and other energetic stressors is unique to humans or is more widely characteristic of large-brained primates.

\section{Materials and Methods}

Study Population and Sample. Detailed contextual information for the Shuar is provided elsewhere $(27,63,76)$. Briefly, the Shuar are an indigenous population of $\sim 50,000$ living predominantly in Amazonian Ecuador. Mixed forager-horticulturalists relying on slash-and-burn horticulture, hunting fishing, and foraging, they exhibit varying degrees of market integration. This study was performed under the Shuar Health and Life History Project (SHLHP) during annual dry seasons between 2011 and 2014. Data were collected in four rural communities, two each in the Upano Valley (UV) and the more isolated cross-Cutucú (CC) geographical regions. Despite some regional differences, children in both the UV and CC consume carbohydratedominant, low-nutrient-density diets typical of northwest Amazonia (63, 76 77) and experience high parasitic and infectious disease rates with limited access to Western medicine (24-26). The Shuar continue to spend much of their time in domestic and subsistence-related activities (78), consistent with high physical activity levels documented among other Amazonian foragerhorticulturalists (79). In total, 261 children ( $n=157$ females and 104 males; generally healthy and not using medication) participated. To ensure par ticipants were large enough for knemometry (see below), only children $4+y$ old were recruited. Individuals over 11 y old or showing overt signs of puberty were excluded to minimize confounding pubertal endocrine effects. Birthdates were typically available from government-issued identity cards and were validated using extensive SHLHP genealogies. Parental informed consent with child informed assent was obtained from all participants. Study methods and procedures were approved and conducted in accordance with guidelines set by village leaders, the Federación Interprovincial de Centros Shuar, and the Committee on the Use of Human Subjects Institutional Review Boards of the University of Oregon and Harvard University. The deidentified datasets and code supporting this article are available from S.S.U. on request (in accordance with privacy concerns and to ensure that the expectations of study participants are understood by other researchers).

Data Collection. Anthropometric data and finger-prick dried blood spot (DBS) samples were collected from children on days of school attendance using conventional methods $(80,81)$. To avoid interobserver error, all such data were collected by S.S.U. Skinfold thickness in four locations (biceps, triceps, subscapular, suprailiac) was measured in triplicate to the nearest $0.5 \mathrm{~mm}$ using precision calipers (Beta Technology). Lower leg length was measured to the nearest $0.01 \mathrm{~mm}$ using a portable knemometer with a $0.18-\mathrm{mm}$ technical error of measurement (28). Knemometry has been widely validated for monitoring weekly child growth $(29,30)$. Our rigorous knemometry protocol involves four replicate length estimates per measurement and numerous diurnal controls (28). Following collection, DBS samples were stored at $-20^{\circ} \mathrm{C}$ via a solar-powered freezer until shipped to the United States for storage at $-30^{\circ} \mathrm{C}$. Data (i.e., height, weight, lower leg length, skinfolds, DBS samples for biomarker analysis) were collected from all participants at study baseline. Current symptoms of infection were not recorded. Followup measures of lower leg length and DBS samples were collected weekly for a subsample of participants $(n=132)$ for up to five consecutive weeks. Follow-up height measurements were collected at 3 mo (mean $=3.0, \mathrm{SD}=$ $0.2, n=177)$ and 20 mo (mean $=20.4, S D=1.5, n=85)$ postbaseline. Participants involved in the longitudinal portions of the study did not differ from the overall sample in age, HAZ, skinfolds, or immune biomarker levels (all $P>0.1$ ).

Immune Biomarker Analysis. Concentrations of biomarkers were measured using ELISA protocols validated for DBS samples. Concentrations of CRP (19, 82) and EBV-Ab (83) were determined using published high-sensitivity protocols. Total IgG and IgE were determined using commercial kits (Bethyl Laboratories) modified for use with DBS. Samples were measured in duplicate with controls on each plate. Intra- and interassay measurement coefficients of variation (CVs) are provided in Table S6. The CRP concentration was measured in all samples. Concentrations of EBV-Ab, IgG, and IgE were measured only in samples collected at baseline. All final participants were seropositive for EBV infection.

Statistical Analysis. For descriptive purposes only, anthropometric z-scores were calculated using US Centers for Disease Control and Prevention (CDC) growth references (31). Measures of HAZ for use in statistical analyses were calculated from Shuar population-specific references (27). Three-months and 20-mo growth measures were standardized to $90-\mathrm{d}$ and $600-\mathrm{d}$ periods, respectively. The knemometry $95 \%$ confidence limit of growth detection was $0.36 \mathrm{~mm}$. Thus, measures of $1-w \mathrm{k}$ growth below $0.36 \mathrm{~mm}$ were replaced with a common value of $0.25 \mathrm{~mm}(0.36 / \sqrt{ } 2)$. The sum of four skinfold measurements provided a final index of body fat (84). To control for ontogenetic differences in adiposity (20), children were categorized into high or low body fat groups based on age- and sex-specific skinfold median sample values (Table S7).

Concentrations of IgE, IgG, and EBV-Ab were natural log-transformed before analysis. To maximize interpretability, CRP DBS measures were converted to serum equivalents using an equation derived from 40 matched serum:DBS samples $\left(C_{\text {SRP }}\right.$ serum $\left.=\mathrm{e}^{[1.2 \times \text { InCRPDBS }+0.3405]} ; r^{2}=0.87\right)$. Partial correlations controlling for age and sex indicate a modest positive correlation of Ig levels (Table S8). For all analyses, serum-equivalent CRP concentration was treated as a binary variable indicating either the presence (CRP $\geq 1 \mathrm{mg} / \mathrm{L}$ ) or absence (CRP $<1 \mathrm{mg} / \mathrm{L}$ ) of acute inflammatory response (85). Only $3 \%$ of participants exhibited three consecutive weeks of CRP elevation $\geq 1 \mathrm{mg} / \mathrm{L}$, and none had CRP $\geq 1 \mathrm{mg} / \mathrm{L}$ over four consecutive weeks. This is consistent with data reported for Shuar adults (86) and supports our use of CRP $\geq 1 \mathrm{mg} / \mathrm{L}$ as a cutoff to identify episodically occurring acute, rather than chronic, inflammation.

Tradeoff relationships between immune biomarkers and growth (P1 and P2) were investigated using linear mixed-effects models. Separate models were constructed for 1-wk growth, 3-mo growth, 20-mo growth, and HAZ. Final model parameters and sample sizes are presented in Table 4. All models included the four immune biomarkers as predictor fixed effects (entered simultaneously), covariate fixed effects for participant age, sex, and body fat group, and a random community term. The 1-wk growth model included an additional random participant term to account for repeated measures. Preliminary models included a dummy fixed effect for geographical region (UV or CC), a possible socioecological confounder. To account for possible between-individual differences in catch-up growth, preliminary prospective growth models also included a fixed effect term for HAZ at baseline. The role of body fat in moderating relationships between immune biomarkers and growth (P3) was investigated using two-way biomarker $\times$ body fat group interaction terms included in all preliminary models. Model selection was performed using Akaike information criterion and likelihood ratio tests with Satterthwaite approximations of degrees of freedom. Nonsignificant interaction terms and covariates not significantly improving model fit were removed from all final models. Post hoc diagnostic analyses revealed 
acceptable degrees of model linearity, heteroscedasticity, and multicollinearity. Analyses were performed in R (cran.us.r-project.org/) using the Ime4 package (87) with the ImeTest extension. Results were considered significant at $P<0.05$.

1. Gadgil M, Bossert W (1970) Life historical consequences of natural selection. Am Nat 104:1-24.

2. Stearns SC (1992) The Evolution of Life Histories (Oxford Univ Press, Oxford).

3. Zera AJ, Harshman LG (2001) The physiology of life history trade-offs in animals. Annu Rev Ecol Syst 32:95-126.

4. Roff DA, Fairbairn DJ (2007) The evolution of trade-offs: Where are we? J Evol Biol 20 433-447.

5. Wolowczuk I, et al. (2008) Feeding our immune system: Impact on metabolism. Clin Dev Immunol 2008:1-19.

6. Biolo G, et al. (1997) Metabolic response to injury and sepsis: Changes in protein metabolism. Nutrition 13(Suppl):52S-57S

7. Muehlenbein MP, Hirschtick JL, Bonner JZ, Swartz AM (2010) Toward quantifying the usage costs of human immunity: Altered metabolic rates and hormone levels during acute immune activation in men. Am J Hum Biol 22:546-556.

8. Lochmiller RL, Deerenberg C (2000) Trade-offs in evolutionary immunology: Just what is the cost of immunity? Oikos 88:87-98.

9. Demas G, Nelson R (2011) Ecoimmunology (Oxford Univ Press, Oxford).

10. Sheldon BC, Verhulst S (1996) Ecological immunology: Costly parasite defences and trade-offs in evolutionary ecology. Trends Ecol Evol 11:317-321.

11. Bogin B, Smith BH (1996) Evolution of the human life cycle. Am J Hum Biol 8:703-716.

12. Kuzawa CW, et al. (2014) Metabolic costs and evolutionary implications of human brain development. Proc Natl Acad Sci USA 111:13010-13015.

13. Kuzawa CW (1998) Adipose tissue in human infancy and childhood: An evolutionary perspective. Am J Phys Anthropol 107:177-209.

14. McDade TW (2003) Life history theory and the immune system: Steps toward a human ecological immunology. Am J Phys Anthropol 122:100-125.

15. Tanner JM (1981) A History of the Study of Human Growth (Cambridge Univ Press, Cambridge, UK)

16. Solomons NW, Mazariegos M, Brown KH, Klasing K (1993) The underprivileged, developing country child: Environmental contamination and growth failure revisited. Nutr Rev 51:327-332.

17. Wells JC (2010) The Evolutionary Biology of Human Body Fatness: Thrift and Control (Cambridge Univ Press, Cambridge, UK)

18. McDade TW, Reyes-García V, Tanner S, Huanca T, Leonard WR (2008) Maintenance versus growth: Investigating the costs of immune activation among children in lowland Bolivia. Am J Phys Anthropol 136:478-484.

19. Blackwell AD, Snodgrass JJ, Madimenos FC, Sugiyama LS (2010) Life history, immune function, and intestinal helminths: Trade-offs among immunoglobulin $\mathrm{E}, \mathrm{C}$-reactive protein, and growth in an Amazonian population. Am J Hum Biol 22:836-848.

20. McCarthy HD, Cole TJ, Fry T, Jebb SA, Prentice AM (2006) Body fat reference curves for children. Int J Obes 30:598-602.

21. Blurton Jones N (2016) Demography and Evolutionary Ecology of Hadza HunterGatherers (Cambridge Univ Press, Cambridge, UK).

22. Hill KR, Hurtado AM (1996) Ache Life History: The Ecology and Demography of a Foraging People (Transaction Publishers, Piscataway, NJ).

23. Kroeger A, llechkova E (1983) Salud y alimentación entre los Shuar (Mundo Shuar, Sucua, Ecuador)

24. Cepon-Robins TJ, et al. (2014) Soil-transmitted helminth prevalence and infection intensity among geographically and economically distinct Shuar communities in the Ecuadorian Amazon. J Parasitol 100:598-607.

25. Jokisch BD, McSweeney K (2006) Informe sobre los Resultados del Diagnóstico de la Situacion de Salud y de los Servicios de Salud de las Nacionalidades Shuar y Achuar FICSH-FIPSE-FINAE 2005 (Ohio State University, Columbus, OH).

26. Gildner TE, et al. (2016) Regional variation in Ascaris lumbricoides and Trichuris trichiura infections by age cohort and sex: Effects of market integration among the indigenous Shuar of Amazonian Ecuador. J Physiol Anthropol 35:28.

27. Urlacher SS, et al. (2016) Physical growth of the Shuar: Height, weight, and BMI references for an indigenous Amazonian population. Am J Hum Biol 28:16-30.

28. Urlacher SS, et al. (2016) The application of knemometry to measure childhood shortterm growth among the indigenous Shuar of Ecuador. Am J Phys Anthropol 160: 353-357.

29. Wolthers OD (2010) Methodology and implications of knemometry in growth assessment of inhaled glucocorticoids. Pediatr Allergy Immunol 21:e190-e198.

30. Hermanussen M (1988) Knemometry, a new tool for the investigation of growth. A review. Eur J Pediatr 147:350-355.

31. Kuczmarski RJ, et al. (2002) 2000 CDC growth charts for the United States: Methods and development. Vital Health Stat, 1-190.

32. Blackwell $A D$, et al. (2017) Growth references for Tsimane forager-horticulturalists of the Bolivian Amazon. Am J Phys Anthropol 162:441-461.

33. Decaro JA, Decaro E, Worthman CM (2010) Sex differences in child nutritional and immunological status 5-9 years post contact in fringe highland Papua New Guinea. Am J Hum Biol 22:657-666.

34. Blackwell AD, et al. (2016) Immune function in Amazonian horticulturalists. Ann Hum Biol 43:382-396.

35. Wander K, Brindle E, O'connor KA (2012) Sensitivity and specificity of C-reactive protein and $\alpha(1)$-acid glycoprotein for episodes of acute infection among children in Kilimanjaro, Tanzania. Am J Hum Biol 24:565-568.
ACKNOWLEDGMENTS. We thank the Shuar. This work was supported by National Science Foundation Grants BCS-1340958 and DGE-1144152, the Leakey Foundation, Harvard University, and the University of Oregon.

36. Konishi S, et al. (2014) Significant sex difference in the association between C-reactive protein concentration and anthropometry among 13- to 19-year olds, but not 6 - to 12-year olds in Nepal. Am J Phys Anthropol 154:42-51.

37. Pepys MB, Hirschfield GM (2003) C-reactive protein: A critical update. J Clin Invest 111 1805-1812.

38. Mcdade TW (2007) Measuring immune function: Markers of cell-mediated immunity and inflammation in dried blood spots. Measuring Stress in Humans: A Practical Guide for the Field, eds Ice G, James G (Cambridge Univ Press, Cambridge, UK), pp 181-208.

39. Abbas AK, Lichtman AH, Pillai S (2014) Cellular and Molecular Immunology (Elsevier Health Sciences, Philadelphia).

40. Iancovici Kidon M, et al. (2005) Serum immunoglobulin E levels in Israeli-Ethiopian children: Environment and genetics. Isr Med Assoc J 7:799-802.

41. Filteau SM, et al. (1995) Vitamin A supplementation, morbidity, and serum acute phase proteins in young Ghanaian children. Am J Clin Nutr 62:434-438.

42. McDade TW, Georgiev AV, Kuzawa CW (2016) Trade-offs between acquired and in nate immune defenses in humans. Evol Med Public Health 2016:1-16.

43. Derting TL, Compton S (2003) Immune response, not immune maintenance, is energetically costly in wild white-footed mice (Peromyscus leucopus). Physiol Biochem Zool 76:744-752.

44. Sederquist B, Fernandez-Vojvodich P, Zaman F, Sävendahl L (2014) Recent research on the growth plate: Impact of inflammatory cytokines on longitudinal bone growth J Mol Endocrinol 53:T35-T44.

45. Collinson A, Moore S, O'Connell M, Charalambos C, Prentice A (2005) Developmental changes in leptin as a measure of energy status in human infants in a natural ecologic setting. Am J Clin Nutr 81:488-494.

46. Gat-Yablonski G, Phillip M (2008) Leptin and regulation of linear growth. Curr Opin Clin Nutr Metab Care 11:303-308.

47. Barker DJ (1995) Fetal origins of coronary heart disease. BMJ 311:171-174.

48. Bateson P, et al. (2004) Developmental plasticity and human health. Nature 430 419-421.

49. Gluckman PD, Hanson MA (2006) Developmental Origins of Health and Disease (Cambridge Univ Press, Cambridge, UK)

50. Crimmins EM, Finch CE (2006) Infection, inflammation, height, and longevity. Proc Natl Acad Sci USA 103:498-503.

51. Hoffman DJ, Martins PA, Roberts SB, Sawaya AL (2007) Body fat distribution in stunted compared with normal-height children from the shantytowns of São Paulo, Brazil. Nutrition 23:640-646.

52. Schroeder DG, Martorell R, Flores R (1999) Infant and child growth and fatness and fat distribution in Guatemalan adults. Am J Epidemiol 149:177-185.

53. Leonard WR, Sorensen MV, Mosher MJ, Spitsyn V, Comuzzie AG (2009) Reduced fat oxidation and obesity risks among the Buryat of Southern Siberia. Am J Hum Biol 21 664-670.

54. Hoffman DJ, Sawaya AL, Verreschi I, Tucker KL, Roberts SB (2000) Why are nutritionally stunted children at increased risk of obesity? Studies of metabolic rate and fat oxidation in shantytown children from São Paulo, Brazil. Am J Clin Nutr 72:702-707.

55. Frisancho AR (2003) Reduced rate of fat oxidation: A metabolic pathway to obesity in the developing nations. Am J Hum Biol 15:522-532.

56. Samaras K, Botelho NK, Chisholm DJ, Lord RV (2010) Subcutaneous and visceral adipose tissue gene expression of serum adipokines that predict type 2 diabetes. Obesity (Silver Spring) 18:884-889

57. Xu H, et al. (2003) Chronic inflammation in fat plays a crucial role in the development of obesity-related insulin resistance. J Clin Invest 112:1821-1830.

58. De Benedetti $F$, et al. (1997) Interleukin 6 causes growth impairment in transgenic mice through a decrease in insulin-like growth factor-I. A model for stunted growth in children with chronic inflammation. J Clin Invest 99:643-650.

59. Berryman DE, Glad CA, List EO, Johannsson G (2013) The GH/IGF-1 axis in obesity: Pathophysiology and therapeutic considerations. Nat Rev Endocrinol 9:346-356.

60. McDade TW, et al. (2017) Social and physical environments early in development predict DNA methylation of inflammatory genes in young adulthood. Proc Natl Acad Sci USA 114:7611-7616.

61. Hoffman DJ, Campos-Ponce M, Taddei CR, Doak CM (2017) Microbiome, growth retardation and metabolism: Are they related? Ann Hum Biol 44:201-207.

62. de Onis $\mathrm{M}$, Blössner $\mathrm{M}$, Borghi $\mathrm{E}$ (2012) Prevalence and trends of stunting among preschool children, 1990-2020. Public Health Nutr 15:142-148.

63. Urlacher SS, et al. (2016) Heterogeneous effects of market integration on sub-adult body size and nutritional status among the Shuar of Amazonian Ecuador. Ann Hum Biol 43:316-329

64. Stephensen CB (1999) Burden of infection on growth failure. J Nutr 129(2S Suppl): 534S-538S.

65. Lampl M, Veldhuis JD, Johnson ML (1992) Saltation and stasis: A model of human growth. Science 258:801-803.

66. Keusch GT, et al. (2014) Environmental enteric dysfunction: Pathogenesis, diagnosis, and clinical consequences. Clin Infect Dis 59(Suppl 4):S207-S212.

67. Urlacher SS, Kramer KL (2018) Evidence for energetic tradeoffs between physica activity and childhood growth across the nutritional transition. Sci Rep 8:369.

68. Gurven M, Walker R (2006) Energetic demand of multiple dependents and the evolution of slow human growth. Proc Biol Sci 273:835-841. 
69. Samaras TT (2007) Human Body Size and the Laws of Scaling: Physiological, Performance, Growth, Longevity and Ecological Ramifications (Nova Science Publishers, New York).

70. Ellison PT (1981) Prediction of age at menarche from annual height increments. Am Phys Anthropol 56:71-75.

71. Kuzawa CW, Bragg JM (2013) Plasticity in human life history strategy. Curr Anthropol 53(Suppl 6):S369-S382.

72. Walker R, et al. (2006) Growth rates and life histories in twenty-two small-scale societies. Am J Hum Biol 18:295-311.

73. Zihlman AL, Bolter DR (2015) Body composition in Pan paniscus compared with Homo sapiens has implications for changes during human evolution. Proc Natl Acad Sci USA 112:7466-7471

74. Antón SC, Potts R, Aiello LC (2014) Human evolution. Evolution of early Homo: An integrated biological perspective. Science 345:1236828.

75. Pontzer $\mathrm{H}$, et al. (2016) Metabolic acceleration and the evolution of human brain size and life history. Nature 533:390-392.

76. Liebert MA, et al. (2013) Implications of market integration for cardiovascular and metabolic health among an indigenous Amazonian Ecuadorian population. Ann Hum Biol 40:228-242.

77. Dufour DL, Piperata BA, Murrieta RS, Wilson WM, Williams DD (2016) Amazonian foods and implications for human biology. Ann Hum Biol 43:330-348.
78. Lu F, Fariss B, Bilsborrow RE (2010) Gendered time allocation of indigenous peoples in the Ecuadorian Amazon. Ethnology 48:239-268.

79. Gurven M, Jaeggi AV, Kaplan H, Cummings D (2013) Physical activity and modernization among Bolivian Amerindians. PLoS One 8:e55679.

80. Lohman TG, Roche AF, Martorell R (1988) Anthropometric Standardization Reference Manual (Human Kinetics Books, Champaign, IL).

81. McDade TW, Williams S, Snodgrass JJ (2007) What a drop can do: Dried blood spots as a minimally invasive method for integrating biomarkers into population-based research. Demography 44:899-925.

82. McDade TW, Burhop J, Dohnal J (2004) High-sensitivity enzyme immunoassay for C-reactive protein in dried blood spots. Clin Chem 50:652-654.

83. Eick G, Urlacher SS, McDade TW, Kowal P, Snodgrass JJ (2016) Validation of an optimized ELISA for quantitative assessment of Epstein-Barr virus antibodies from dried blood spots. Biodemogr Soc Biol 62:222-233.

84. Gibson RS (2005) Principles of Nutritional Assessment (Oxford Univ Press, Oxford).

85. McDade TW, et al. (2005) Predictors of C-reactive protein in Tsimane' 2 to 15 year-olds in lowland Bolivia. Am J Phys Anthropol 128:906-913.

86. McDade TW, et al. (2012) Analysis of variability of high sensitivity C-reactive protein in lowland Ecuador reveals no evidence of chronic low-grade inflammation. Am J Hum Biol 24:675-681.

87. Bates $D$, Maechler M, Bolker B, Walker S (2015) Fitting linear mixed-effects models using Ime4. J Stat Softw, 10.18637/jss.v067.i01. 